\title{
Literacy and cognitive change among ethnically diverse elders
}

\author{
Jennifer J. Manly, Desiree Byrd, Pegah Touradji, Danurys Sanchez, and Yaakov Stern \\ Columbia University College of Physicians and Surgeons, New York, USA
}

\begin{abstract}
$R$ esearch concerned with relations between literacy level and assessment of cognition among ethnically diverse elders is presented. The evidence suggests that literacy has a profound effect on neuropsychological measures across verbal and nonverbal domains, and that this effect is independent of other demographic and experiential factors such as age, years of education, sex, ethnicity, and language use. It appears that reading level is a more sensitive predictor of baseline test performance, and also that literacy skills are protective against memory decline. Adjustment for reading level, which in part reflects quality of education, overcomes the limitations of years of education as an index of educational experience among multicultural elders and thus can improve the specificity of certain neuropsychological measures. Differences in organization of visuospatial information, lack of previous exposure to stimuli, and difficulties with interpretation of the logical functions of language are possible factors that affect test performance of elders with low levels of literacy.
\end{abstract}

$U$ ne recherche portant sur les relations entre le niveau d'alphabétisation et l'évaluation de la cognition chez les aînés de diverses ethnies est présentée. Les études antérieures suggèrent que l'alphabétisation a un effet marqué sur les mesures neuropsychologiques à travers les domaines verbaux et non verbaux et que cet effet est indépendant d'autres facteurs démographiques et expérimentaux tels que l'âge, le nombre d'années de scolarité, le sexe, le groupe ethnique et la langue utilisée. Il apparaît que le niveau de lecture est un prédicteur plus sensible de la performance de base à un test et aussi que les habiletés d'alphabétisation protègent contre le déclin de la mémoire. L'adaptation au niveau de lecture, lequel reflète en partie la qualité de l'éducation, surpasse les limites associées au nombre d'années de scolarité en tant qu'indice d'expérience éducative chez des personnes âgées de différentes cultures et, ainsi, peut améliorer la spécificité de certaines mesures neuropsychologiques. Les différences dans l'organisation d'informations visuospatiales, le manque d'exposition antérieure aux stimuli et les difficultés avec l'interprétation des fonctions logiques du langage sont des facteurs pouvant potentiellement avoir un impact sur la performance au test chez les aînés ayant de faibles niveaux d'alphabétisation.

S e presenta una investigación acerca de la relación entre el nivel educativo y la evaluación de habilidades $\int$ cognitivas en adultos de diferentes grupos culturales (etnias). Los hallazgos sugieren que la educación tiene un profundo efecto en medidas neuropsicológicas tanto en áreas verbales como no verbales, y que este efecto es independiente de otros factores demográficos y de experiencia como la edad, años de educación, sexo, etnicidad y uso del lenguaje. Al parecer, el nivel de lectura es un predictor más sensible del desempeño inicial en las pruebas, y las habilidades de lectura y escritura (literacy skills) protegen del deterioro de la memoria. Ajustar puntajes de acuerdo al nivel de lectura, lo cual refleja la calidad de la educación, supera las limitaciones de tomar los años de educación como un índice de experiencia educacional entre adultos de diferentes grupos culturales mejorando la especificidad de ciertas medidas neuropsicológicas. Los factores que afectan el desempeño de adultos con bajo nivel educativo incluye diferencias en la organización de información visoespacial, falta de exposición previa a los estímulos y a dificultades en la interpretación de las funciones lógicas del lenguaje.

Correspondence should be sent to Jennifer Manly, PhD, G. H. Sergievsky Center, 630 West 168th Street P\& S Box 16, New York, NY 10032, USA (E-mail: jjm71@columbia.edu).

This research was supported by federal grants AG16206 (J. Manly), AG07232 (R. Mayeux), the Alzheimer's Association, and the New York City Speakers Fund for Biomedical Research-Toward the Science of Patient Care. The authors thank Rosann Costa for her help with data management, Maria Gonzalez-Diaz, Cherita McDowell, and Judes Fleurimont for assistance with scheduling and interviewing participants.

(C) 2004 International Union of Psychological Science 
During the infancy of the field of neuropsychology, Vygotsky $(1962,1978)$ suggested that the development and organization of basic psychological processes such as abstraction, inference, and memory depended on the type of symbols (e.g., writing systems) used by individuals in their environment. Luria (1976) followed this work with a study of illiterate, unschooled individuals; he found that they solved cognitive problems in a context-bound manner and were more influenced by the perceptual and functional attributes of a stimulus than were schooled literates, who were more responsive to abstract concepts and logical relationships among stimuli. As a result of their studies of the Vai people in Liberia, Scribner and Cole (1981) concluded that although literacy is not necessary for the development of logic, abstraction, memory, and communication skills, the nature of writing systems and the way in which they are used affect the organization and expression of these cognitive abilities.

These early studies led a number of investigators to describe the influence of literacy level on specific neuropsychological measures as a reflection of underlying brain function. Several authors have reported poor performance of illiterate individuals on language tasks such as repetition of psuedowords, recall of phonologically related word associates, word list, sentence, and story recall, phonemic or letter fluency tasks, naming, and auditory comprehension (Lecours et al., 1987; Reis \& Castro-Caldas, 1997; Reis, Guerreiro, \& Castro-Caldas, 1994). The authors concluded that the illiterates' lack of grapheme-phoneme correspondence explained their performance on these language-based measures. However, discrepancies in the cognitive test performance of literates and illiterates are not restricted to tasks involving phonemic skills; effects of reading and writing ability have been reported on measures of figure memory, visuospatial ability (copy of simple and complex figures, time-telling, recognition of superimposed figures, stick constructions), digit span, naming, calculation, praxis, alternating movements, and cancellation tasks (Ardila, Rosselli, \& Rosas, 1989; Rosselli, Ardila, \& Rosas, 1990).

The purpose of this article is to summarize our research on literacy and neuropsychological test performance, and place this work in the context of prior studies on the effect of reading and writing skill on cognitive ability. Our work has been concerned with improving the specificity of neuropsychological measures among ethnically diverse elders; therefore, the discussion will focus on the interrelationships between age, race, culture, formal schooling, and quality of education.

The participants for our research described below were selected from the Washington Heights Inwood Columbia Aging Project (WHICAP), a community-based, epidemiological study of dementia in the ethnically diverse neighbourhoods of Northern Manhattan, NY. The WHICAP study follows a random sample of elderly Medicare recipients above age 65 residing in selected census tracts of Washington Heights and Inwood. The population from which participants were drawn is comprised of individuals from several different countries of origin, representing three broadly defined ethnic categories (i.e., Hispanic, African American, and white). Approximately $6.5 \%$ of the overall cohort report that they are illiterate. Interviews and neuropsychological testing were conducted in English or Spanish, according to the subject's wishes.

The neuropsychological measures used in these studies were selected to assess cognitive functions that are typically affected in dementia and have been shown to effectively distinguish between normal ageing and dementia in this community (Stern et al., 1992). The evaluation included measures of learning and memory, orientation, abstract reasoning, language, and visuospatial ability. Specific ability areas and tests administered include: verbal list learning and memory (Selective Reminding Test [SRT], Buschke \& Fuld, 1974); nonverbal memory (multiple choice version of the Benton Visual Retention Test [BVRT], Benton, 1955); orientation (items from the Mini Mental State Examination [MMSE], Folstein, Folstein, \& McHugh, 1975); verbal reasoning (Similarities subtest of the Wechsler Adult Intelligence Scale-Revised [WAIS-R], Wechsler, 1981); nonverbal reasoning (Identities and Oddities subtest of the Mattis Dementia Rating Scale, Mattis, 1976); naming (15-item version of the Boston Naming Test, Kaplan, Goodglass, \& Weintraub, 1983); letter fluency (Controlled Word Association, Benton \& Hamsher, 1976; Jacobs, Sano, Albert, Schofield, Dooneief, \& Stern, 1997); category fluency (animals, food, and clothing, using procedures from the Boston Diagnostic Aphasia Examination [BDAE], Goodglass \& Kaplan, 1983); repetition (high-frequency phrases of the BDAE, Goodglass \& Kaplan, 1983); auditory comprehension (first six items of the Complex Ideational Material subtest of the BDAE, Goodglass \& Kaplan, 1983); visuoconstruction (Rosen Drawing Test, Rosen, 1981); and visuoperceptual skills (multiple-choice 
matching of figures from the BVRT, Benton, 1955).

All interview questions, test instructions, and stimuli were translated into Spanish by a committee of Spanish speakers from Cuba, Puerto Rico, Spain, and the Dominican Republic, and then back-translated to ensure accuracy. Test items were translated literally. Where necessary, scoring criteria were modified so as to give credit for responses reflecting regional idioms. The Spanish version of the battery is described in detail elsewhere (Jacobs et al., 1997). Evaluations were conducted in either English or Spanish, based on the subject's opinion of which language would yield the best performance. Examiners were balanced bilinguals who spoke both English and Spanish daily with friends, family, and colleagues.

From an examination of medical, psychiatric, and neurological functioning, as well as from a measurement of functional status (Blessed, Tomlinson, \& Roth, 1968; Boller, Mizutani, Roessmann, \& Gambetti, 1980), a physician independently determined whether each participant met criteria for dementia using the Diagnostic and Statistical Manual of Mental Disorders-Revised, 3rd ed. (American Psychiatric Association, 1987) criteria. Participants were excluded from the research described below if they had a history of Parkinson's disease, stroke, alcohol abuse, or major psychiatric illness.

\section{COGNITIVE TEST PERFORMANCE AMONG ILLITERATES AND LITERATES WITH NO FORMAL EDUCATION}

Results of prior research suggest that literacy level has a significant influence on the nature of performance on traditional neuropsychological measures of verbal and nonverbal skills; however, many studies were unable to distinguish between the effects of literacy and the effects of little or no exposure to formal education. In our group's earliest work in this area (Manly et al., 1999) we intended to address this limitation by comparing the test performance of unschooled nondemented literate and illiterate elders on a dementia battery. That is, we were able to distinguish the effects of literacy alone versus those associated with formal education, since in addition to those who never learned to read and write there were many elders in our sample who were literate but who had received little or no formal education.

At the time of the neuropsychological evaluation, we asked participants "Did you ever learn to read and write?" as a part of a survey questionnaire.
Generally, illiterate elders in the study were born and raised in rural communities in the Caribbean or the southern United States, where formal schooling was unavailable or where they were required to work at an early age. When these individuals came to New York City, they usually obtained jobs that did not require reading or writing skills, and many of the women worked as housewives. Literates with no formal education usually learned to read and write from siblings at home.

Twenty-six literate and 47 illiterate nondemented elders with no formal education, who were equivalent on age and functional status, participated in the study. There were equal proportions of women in each group, but there was a higher proportion of Spanish-speakers in the illiterate group (92\%) as compared to the literate group $(65 \%)$. Significantly more illiterates $(66 \%)$ could not perform, or refused to perform, the letter fluency task as compared to literates $(19 \%)$. Multivariate analyses revealed significant effects of both language and literacy on overall test performance, with no significant interaction effect. Univariate testing showed that, independent of language, illiterates obtained significantly lower scores on BVRT recognition memory, WAIS-R Similarities, BDAE Repetition, and BVRT matching than literates (Table 1). There were no significant effects of language on individual test scores, and the results did not change when we limited the analyses to Spanish-speakers.

We concluded that overall, illiterates obtained significantly lower neuropsychological test scores than education-matched literates. The overall effect of literacy status remained significant when the analysis was limited to those with no formal schooling and when the potential effect of language of test administration was controlled. Because our sample included individuals who had learned to read and write, yet had received no formal schooling, we were able to control for the major environmental influence of formal education and test for the effects of literacy status alone. Our finding that literacy status had no effect on delayed recall or semantic fluency is promising for assessing illiterate elders for dementia, since memory dysfunction and semantic fluency impairment are hallmark signs of dementia and rapid forgetting is particularity important for the diagnosis of Alzheimer's disease (e.g., Bondi, Salmon, \& Butters, 1994; Troster et al., 1993; Welsh, Butters, Hughes, Mohs, \& Heyman, 1992). 
TABLE 1

Cognitive test scores of literate $(n=26)$ and illiterate $(n=47)$ elders with no formal education

\begin{tabular}{|c|c|c|c|c|}
\hline \multirow[b]{2}{*}{ Test } & \multirow[b]{2}{*}{ Literate } & \multirow[b]{2}{*}{ Illiterate } & \multicolumn{2}{|c|}{ Effect of literacy ${ }^{a}$} \\
\hline & & & $F$ & $p$ \\
\hline \multicolumn{5}{|l|}{ Learning/memory } \\
\hline SRT total recall & $32.08(10.90)$ & $28.11(7.29)$ & 5.06 & .028 \\
\hline SRT delayed recall & $4.31(2.69)$ & $3.57(1.92)$ & 3.26 & .076 \\
\hline BVRT recognition memory & $4.96(2.40)$ & $3.47(1.72)$ & 8.06 & .006 \\
\hline \multicolumn{5}{|l|}{ Orientation } \\
\hline MMSE orientation & $9.32(0.90)$ & $8.44(1.52)$ & 4.83 & .031 \\
\hline \multicolumn{5}{|l|}{ Abstract reasoning } \\
\hline WAIS-R similarities & $7.04(3.25)$ & $5.33(1.57)$ & 10.27 & .002 \\
\hline DRS identities \& oddities & $12.22(3.16)$ & $12.77(2.04)$ & 0.24 & .627 \\
\hline \multicolumn{5}{|l|}{ Language } \\
\hline Boston Naming & $12.74(1.54)$ & $11.24(2.50)$ & 4.89 & .031 \\
\hline Category fluency & $11.34(3.48)$ & $12.15(3.07)$ & 0.28 & .596 \\
\hline BDAE repetition & $7.58(0.83)$ & $7.11(1.15)$ & 7.56 & .008 \\
\hline BDAE comprehension & $4.54(1.38)$ & $3.43(1.39)$ & 3.47 & .067 \\
\hline \multicolumn{5}{|l|}{ Visuospatial ability } \\
\hline Rosen drawing & $1.48(1.04)$ & $0.88(0.88)$ & 4.96 & .030 \\
\hline BVRT matching & $6.52(2.23)$ & $4.79(1.93)$ & 16.98 & .000 \\
\hline
\end{tabular}

SRT = Selective Reminding Test; BVRT = Benton Visual Retention Test; MMSE=Mini-Mental State Examination; WAIS-R = Wechsler Adult Intelligence Scale - Revised; DRS = Dementia Rating Scale; BDAE = Boston Diagnostic Aphasia Examination.

${ }^{a}$ The effect of literacy (literate vs. illiterate) on neuropsychological test score after the effect of language (English vs. Spanish) is accounted for using $2 \times 2$ ANOVA.

\section{SPANISH READING LEVEL, NEUROPSYCHOLOGICAL TEST PERFORMANCE}

Interpretation of the results of our first study was limited because literacy was determined by selfreport rather than measured directly. Recent work, reported here in preliminary form, addresses this limitation by assessing literacy using a reading measure. In this work, we evaluated the relationship of reading level to cognitive test performance among nondemented Spanish-speakers from the same communitybased, epidemiological study. Potential participants self-identified as Hispanic and performed the neuropsychological battery in Spanish.

Reading level was measured using the 30 -item Word Accentuation Test (WAT; Del Ser, GonzalezMontalvo, Martinez-Espinosa, Delgado-Villapalos, \& Bermejo, 1997). This measure was designed to be equivalent to English language measures of reading recognition such as the NART (Nelson, 1982; Nelson \& O'Connell, 1978), which consists of words with an irregular pronunciation whose proper reading would depend on previous knowledge or exposure to the words. This technique is not possible in the Spanish language, since the orthography of Spanish correlates with pronunciation in a regular, rule-based way. The authors of the WAT, which was developed in Spain, developed a measure in which the reader is confronted with an ambiguous graphic clue: infrequent, irregularly stressed words written in capital letters without their accent marks. This format allows for some correspondence with the NART, as correct pronunciation depends on previous knowledge of the words. The authors of the WAT found a Cronbach's $\alpha$ coefficient of internal consistency of .91 and found the measure useful in estimating premorbid intellectual functioning among demented patients. A measure similar to the WAT, but developed for use in Buenos Aires, was reported to have high internal consistency and good concurrent validity with the WAIS Vocabulary subtest and number of years of formal education (Burin, Jorge, Arizaga, \& Paulsen, 2000).

We attempted to administer the WAT to a total of 780 Spanish-speaking elders. However, we did not obtain WAT scores for 30 individuals $(3.9 \%)$. Most of these elders $(n=28)$ had visual deficits and were unable to read the words. The remaining two elders refused to complete the test. Of the 750 elders with WAT scores, 92 were independently diagnosed as demented by a physician. Demographic data for the nondemented and demented participants is presented in Table 2. The majority of these elders identified as Dominican (59.3\%), 
TABLE 2

Demographics for demented and nondemented Hispanic elders

\begin{tabular}{lcllr}
\hline & Nondemented & Demented & t or $\chi^{2}$ & $p$ \\
\hline$N$ & 658 & 92 & & \\
\% female & 67.3 & 77.2 & 3.821 & .05 \\
\% Dominican & 59.1 & 60.5 & & \\
Mean age $(S D)$ & $74.8(5.7)$ & $77.7(6.9)$ & 4.3 & $<.001$ \\
Mean years of education $(S D)$ & $6.4(4.2)$ & $4.8(3.8)$ & 3.4 & .001 \\
Mean WAT reading score $(S D)$ & $13.6(8.6)$ & $9.1(8.5)$ & 4.7 & $<.001$ \\
\hline
\end{tabular}

WAT $=$ Word Accentuation Test.

while there were also Puerto Ricans (13.3\%), Cubans $(19.0 \%)$, and other Hispanics $(8.4 \%)$ in the sample. The majority of the sample $(99 \%)$ reported that Spanish was their first language.

Our first goal was to explore the relationship of WAT scores to overall years of education among the 658 nondemented elders. The raw correlation between the two variables was significant $(r=.53$; $p<.001)$. Figure 1 depicts WAT values for each grade level; the box represents the interquartile range that contains $50 \%$ of values, the lines that extend from the box indicate the highest and lowest values (excluding outliers), and the dark line across the box indicates the median. This figure shows that despite the strong, linear relationship between the two variables, there is a great deal of variability in actual reading ability within each grade level, suggesting that the WAT is tapping into an aspect of educational experience that is not captured by years of schooling alone.

The next question was whether Spanish reading level was a significant independent predictor of neuropsychological test score over and above years of education, age, and sex among

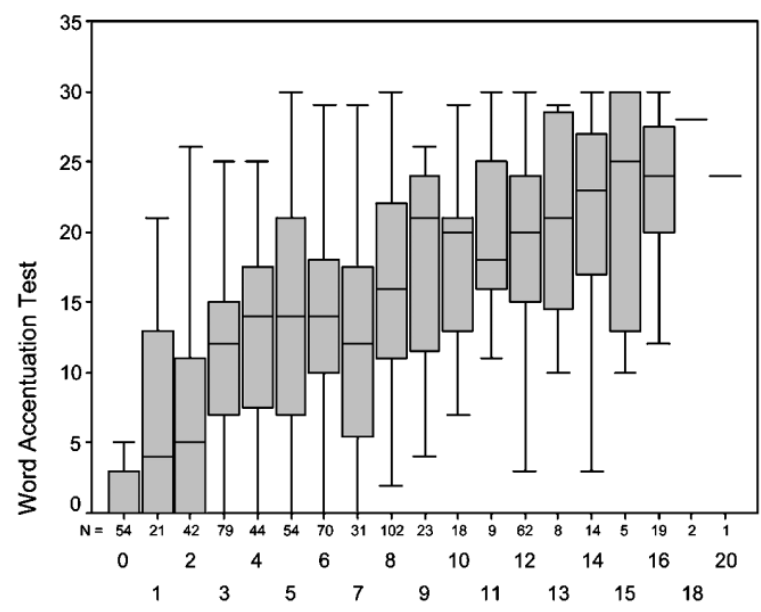

Highest Grade of School Completed

Figure 1. Word Accentuation Test median, interquartile range, and high/low values by grade level. nondemented elders. Multiple regression was used to predict each of the 13 neuropsychological test scores. In each regression equation, demographic variables (age, education, and gender) were entered as a first set of predictors, and then WAT reading level was entered in a final step. The proportion of test variance explained by the two sets of predictors is presented in Table 3 . As is shown, WAT score accounted for a small but significant amount of unique variance measures across cognitive domains, ranging from 1 to $10 \%$ of the overall variance.

These results are similar to those obtained in the Manly et al. (1999) study using self-reported literacy level, and support the conclusion that Spanish literacy has a significant, independent effect on cognitive test performance beyond that predicted by years of education, age, or sex. This effect appears to be strongest on language-based measures such as naming, verbal abstraction, and comprehension, but is also significant in nonverbal domains including drawing and figure matching. It is likely that literates have better developed skills in organization and analysis of certain types of visuospatial information than do individuals who have not learned how to read and write. Alternatively, literates may be successfully using linguistic skills to mediate nonverbal tasks, skills that illiterates cannot access. Line drawings may have been more ambiguous or less recognizable for illiterates, and thus more difficult to name even with a stimulus cue. The relationship of literacy with naming is not a new finding; Reis and her colleagues (Reis et al., 1994) discussed the possibility that learning conventional representations of familiar objects is comparable to learning representations of letters or words. Additionally, illiterates may have less exposure to, or familiarity with, the objects themselves (e.g., camel, cactus, accordion, harp) as a result of their reading limitations. The construction of written language provides literate individuals with practice in the interpretation of complex sentences in which 
TABLE 3

Effect of demographics and WAT reading on neuropsychological test score among nondemented Spanish-speaking elders

\begin{tabular}{lcc}
\hline & $\begin{array}{c}\text { Effect of age, } \\
\text { years of } \\
\text { education, sex } \\
R^{2}\end{array}$ & $\begin{array}{c}\text { Independent effect } \\
\text { of WAT score }\end{array}$ \\
Test & & $\Delta R^{2}$ \\
\hline Learning/Memory & .10 & .03 \\
SRT total recall & .06 & .02 \\
SRT delayed recall & .12 & .05 \\
BVRT recognition memory & & .01 \\
Orientation & .06 & .08 \\
MMSE Orientation & .19 & .04 \\
Abstract reasoning & .04 & .10 \\
WAIS-R Similarities & & .03 \\
DRS Identities \& Oddities & .08 & .02 \\
Language & .07 & .04 \\
Boston Naming & .08 & .08 \\
Letter fluency & .03 & .06 \\
Category fluency & .11 & .07 \\
BDAE repetition & & \\
BDAE comprehension & .12 & .19 \\
Visuospatial skills & & \\
Rosen drawing & & \\
BVRT matching & & \\
\hline
\end{tabular}

SRT $=$ Selective Reminding Test BVRT $=$ Benton Visual Retention Test; MMSE $=$ MiniMental State Examination; WAIS-R $=$ Wechsler Adult Intelligence Scale-Revised; $\mathrm{DRS}=$ Dementia Rating Scale; BDAE $=$ Boston Diagnostic Aphasia Examination .

${ }^{a}$ Except for the effect of WAT on Orientation, all $R^{2}$ are significant below the .001 level.

subject-object order is varied, and in decoding logical relationships from language. We suspect that the relationship of literacy to WAIS-R Similarities subtest performance is driven by factors first described by Luria (1976) and Scribner and Cole (1981): Illiterates may have focused on more practical, concrete aspects of the items or lack the vocabulary to obtain higher scores on the measure.

\section{SPANISH READING LEVEL AND DEMENTIA}

Our next goal was to determine the effect of literacy on decline in cognitive function over time. Low education has been established as a significant risk factor for $\mathrm{AD}$ and other dementias (Kawas \& Katzman, 1999). A higher prevalence of Alzheimer's disease and dementia among elders with low levels of education has been found in Brazil (Caramelli et al., 1997), China (Hill et al., 1993; Zhang et al., 1990), Finland (Sulkava et al., 1985), France (Dartigues et al., 1991), Italy (Bonaiuto et al., 1990; Prencipe, Casini, Ferretti, Lattanzio, Fiorelli, \& Culasso, 1996), Israel (Bowirrat, Treves, Friedland, \& Korczyn, 2001; Korczyn, Kahana, \& Galper, 1991), the Netherlands (Ott et al., 1995), Sweden (Fratiglioni et al., 1991; Gatz, Svedberg,
Pederson, Mortimer, Berg, \& Johansson, 2001), and the United States (Callahan, Hall, Hui, Musick, Unverzagt, \& Hendrie, 1996; Gurland et al., 1995; Mortel, Meyer, Herod, \& Thornby, 1995). Higher incidence of dementia has been demonstrated in several studies (Evans et al., 1993; Letenneur, Commenges, Dartigues \& BarbergerGateau, 1994; Stern, Gurland, Tatemichi, Tang, Wilder, \& Mayeux, 1994; White et al., 1994). Cognitive decline appears to be faster (Stern, Albert, Tang, \& Tsai, 1999; Teri, McCurry, Edland, Kukull, \& Larson, 1995; Unverzagt, Hui, Farlow, Hall, \& Hendrie, 1998) and associated with increased risk of mortality (Stern, Tang, Denaro, \& Mayeux, 1995) among highly educated minorities with Alzheimer's disease, which suggests that the level of brain pathology is greater by the time well-educated individuals show the signs of dementia.

Cognitive reserve has been suggested as the mechanism for the link between low education and higher risk of dementia observed in these studies (Mortimer, 1988; Satz et al., 1993; Stern, 2002). Reserve, or the brain's ability to tolerate the effects of dementia pathology, may result from native ability or from the effects of lifetime experience. Years of education may serve as a proxy for reserve, whether it results from ability 
or experience. In passive models of reserve (Stern, 2002), education would be a proxy for the brain's capacity (synaptic density or complexity) to tolerate either gradual or sudden insult. In active models, years of education would be an indicator of the brain's ability to compensate for pathology through more efficient use of existing cognitive networks or recruitment of alternate networks.

However, there are cases in which the relationship between education and risk for cognitive impairment or dementia is weakened or absent. Two large international studies of incident dementia found that illiteracy or low levels of education did not increase the risk of Alzheimer's disease among elders in India (Chandra et al., 2001) and West Africa ( Hall et al., 1998; Hendrie, 2001). In fact, these studies had the lowest prevalence and incidence rates of dementia observed to date despite the fact that a large proportion of the populations lacked formal schooling or literacy training. This paradox serves to illuminate the difficulty in comparing cultural groups with disparate backgrounds. Reserve is measured by proxy variables (such as years of education, occupational level, or IQ measures), but there are a number of ways in which cultural, racial, and economic factors may affect the predictive power of these proxies. First, it is possible that race- and income-based limits on educational opportunity weaken the relationship between years of education and native ability, leading to underestimates of the relationship between education and cognitive decline. Minorities with strong intellectual abilities may not achieve high levels of academic or occupational status because their opportunities are limited by societal forces (e.g., racism, poverty) unrelated to their native intellect or drive to succeed. Although such individuals may be powerful or influential in their community, their abilities may not be reflected in years of schooling or traditional indicators of occupational status. Alternatively, rather than a reflection of innate ability, years of education could be an indicator of lifetime experiences that change the brain during childhood or adult life and thus create a reserve against disease pathology. However, use of years of education to represent a direct effect of experience on the brain or cognition is also problematic when employed among ethnic minorities and immigrants due to the increased discordance between years of education and quality of education among these groups. For example, there is abundant evidence to suggest (a) that years of education is not a commensurate measure between African Americans and whites and is thus an inadequate estimate of educational experience (Margo, 1985, 1990; Smith, 1984; Smith \& Welch, 1977; Welch, 1966, 1973), and (b) that African Americans have reading skills significantly below their self-reported education level (Albert \& Teresi, 1999; Baker, Johnson, Velli, \& Wiley, 1996; Parasuraman \& Haxby, 1993).

We propose that literacy could be a more sensitive proxy for reserve than years of education because it more accurately reflects the quality of the educational experience provided to ethnic minority elders. In addition, literacy could be a more accurate reflection of native ability because it does not assume that all individuals learn the same amount from a certain grade level, or that some excel more than others; also, the seeking of learning outside of school will be reflected in measurements of literacy. We tested this hypothesis among Hispanic elders using the Spanish literacy measure.

We first wanted to determine whether there was any change in WAT score over time. For this analysis, we used a subset of 126 elders who were administered the WAT twice. The test-retest interval ranged from 1 to 4 years, with a mean of 2.5 years ( $S D=6$ months). The majority of these elders were not demented at baseline (88\%); however, eight of the nondemented elders converted to dementia at follow-up. The overall test-retest reliability of the WAT scores was good (Pearson's $r=.78$ ). Of the eight elders who converted to dementia at their follow-up visit, the test-retest reliability was high (Pearson's $r=.91)$.

Given that the WAT did not show significant change over time among demented or nondemented elders, we used baseline WAT scores in the larger sample $(n=750$, described above) to determine if Spanish reading level was a significant independent predictor of dementia status. A stepwise binary logistic regression was used to determine the best predictors of dementia status (nondemented vs. demented) among the following independent variables: age, sex, years of education, and Spanish reading level. Criteria for entry was set at $p<.01$ in order to strike a balance between the likelihood of committing Type I and Type II errors. This analysis revealed that WAT score was the strongest independent predictor of dementia status, such that Spanish-speaking elders with lower literacy levels were more likely to be demented $(\beta=-.06, p<.001)$. Of the 
possible predictors, age was the only additional variable that entered the equation $(\beta=-.07$, $p<.001)$, indicating that older elders were more likely to be diagnosed with dementia. Our study thus supports a link between literacy level and dementia, and indicates that among Spanishspeaking elders, literacy level is a more sensitive predictor of presence of dementia than years of education. If, as our preliminary data suggests, WAT scores remain stable in the early stages of dementia, literacy may be a more accurate reflection of cognitive reserve than years of schooling.

\section{LITERACY AND MEMORY DECLINE}

The studies reviewed in the previous section focus on the relationship of schooling and literacy to dementia or Alzheimer's disease. But there is also evidence for a role of education in age-related cognitive decline. Several studies of normal ageing have reported more rapid cognitive and functional decline among individuals with lower educational attainment (Albert et al., 1995; Butler, Ashford, \& Snowdon, 1996; Christensen et al., 1997; Chodosh, Reuben, Albert, \& Seeman, 2002; Farmer, Kittner, Rae, Bartko, \& Regier, 1995; Finley, Ardila, \& Roselli, 1991; Snowdon, Ostwald, $\&$ Kane, 1989). These studies suggest that the same education-related factors that delay the onset of dementia also allow individuals to cope more effectively with changes encountered in normal ageing. We designed a study to explore the relationship of literacy level to change in memory ability over time among an ethnically diverse sample of English-speaking nondemented elders (Manly, Touradji, Tang, \& Stern, in press). Specifically, we wanted to determine if literacy was a stronger predictor of memory decline (and thus a more sensitive indicator of reserve) than years of education or racial/ethnic classification, although each of these variables were expected to influence baseline scores. We focused our analyses on immediate and delayed recall measures from a verbal word list learning task, since these measures are sensitive to age-related memory decline and the earliest signs of Alzheimer's disease.

A total of 136 participants with four completed evaluations were stratified into two literacy groups based on the median performance of the group on the WRAT- 3 reading test $($ median $=47$ ). Table 4 presents the demographics of the two groups. As expected, the low literacy group had fewer years of education and low literacy participants were more likely to be ethnic minorities than the high literacy group. The groups did not differ from each other on age or gender composition. Mean follow-up duration was 5.1 years $(S D=1.1)$ and did not differ within the two literacy groups.

Generalized estimating equations (GEE) analyses were performed to determine differences in change in Selective Reminding Test (SRT) total recall performance between the two literacy groups. There was no effect of gender, ethnicity, or interaction of any of these covariates with time on SRT total recall. The final model indicated that age and education had main effects on SRT total recall score in the expected directions, and that there was a significant literacy group effect and a significant time effect. There was also a significant positive Literacy $\times$ Time effect, indicating that the low literacy group had a steeper decline in total recall scores compared with the high literacy group. These results are presented graphically in Figure 2.

Using SRT delayed recall as the dependent variable in a GEE analysis yielded similar results; only years of education was significant among the added covariates, but there was a significant

TABLE 4

Characteristics of the two literacy groups used for analysis

\begin{tabular}{|c|c|c|c|c|c|c|}
\hline & \multicolumn{3}{|c|}{ Low literacy group $(n=67)$} & \multicolumn{3}{|c|}{ High literacy group $(n=69)$} \\
\hline & $M$ & $S D$ & Range & $M$ & $S D$ & Range \\
\hline Age & 79.8 & 5.8 & $67-94$ & 80.3 & 5.2 & $68-94$ \\
\hline Years of education ${ }^{a}$ & 10.6 & 3.4 & $0-16$ & 13.0 & 3.2 & $1-18$ \\
\hline WRAT-3 Reading score ${ }^{\mathrm{b}}$ & 40.3 & 7.8 & $0-47$ & 51.2 & 2.2 & $48-56$ \\
\hline Sex, $\%$ female & 76.1 & & & 63.8 & & \\
\hline Ethnicity, \% minority ${ }^{\mathrm{c}}$ & 76.1 & & & 39.1 & & \\
\hline
\end{tabular}

WRAT-3 = Wide Range Achievement Test-Version 3.

${ }^{\mathrm{a}} t(134)=4.34 ; p<.001$.

${ }^{\mathrm{b}} t(134)=13.22 ; p<.001$.

${ }^{c} \chi^{2}(1)=19.56 ; p<.001$. 


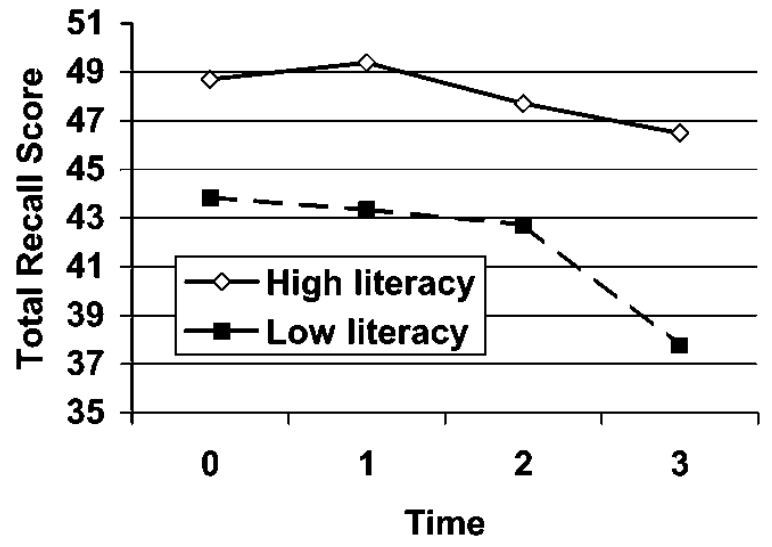

Figure 2. Change in Selective Reminding Test total recall score over time.

literacy group effect and a significant time effect. There was also a significant positive Literacy $x$ Time interaction, indicating that the low literacy group had a steeper decline in delayed recall scores compared with the high literacy group. The profile of SRT delayed recall scores over time for high and low literacy groups is shown in Figure 3.

These results indicate that elders with both high and low levels of literacy declined in immediate and delayed memory over time; however, the decline was more rapid among low literacy elders. This suggests that high literacy skills do not provide complete preservation of memory skills but rather a slowing of age-related decline. All participants had normal overall cognition and were functioning normally in daily activities; thus the decline in memory scores was not associated with the onset of a dementia disorder. There were no interactions between time and either years of education or ethnicity, suggesting that in this diverse population of normal elders, literacy was the most sensitive predictor of memory decline. Unlike

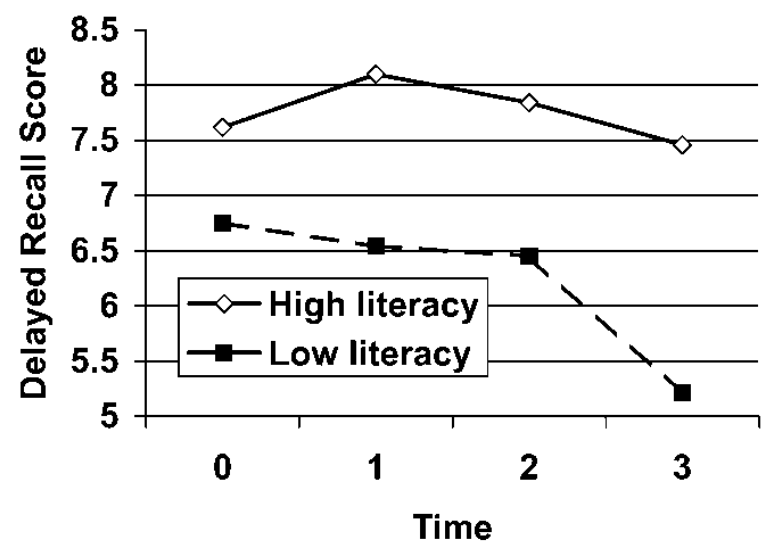

Figure 3. Change in Selective Reminding Test delayed recall score over time. many prior studies that examined the relationship of education to dementia or normal ageing, we did not find that low education (less than 12 years) was a risk factor for cognitive decline.

\section{RACE, READING LEVEL, AND NEUROPSYCHOLOGICAL TEST PERFORMANCE}

Another related line of research has focused on determining the factors that underlie racial group differences in cognitive test performance at a single point in time. It is now well known that African Americans obtain lower scores on neuropsychological tests as compared to non-Hispanic whites (see Manly \& Jacobs, 2001, for review). Investigators frequently use covariance or matching procedures in order to equate racial groups on years of education before comparing neuropsychological test performance, since education often differs between groups of African Americans and whites. Therefore, support of racial group differences depends on whether we can successfully "adjust" for years of education. However, along with several other authors (Kaufman, Cooper, \& McGee, 1997; Loewenstein, Arguelles, Arguelles, \& Linn-Fuentes, 1994; Whitfield \& Baker-Thomas, 1999), we argue that due to the disparities in quality of education reviewed above, matching on quantity of formal education does not necessarily mean that the quality of education received by each racial group is comparable. The variable "years of education" systematically differs between African Americans and whites and is also related to cognitive test performance. If this variable is not commensurate between racial groups, residual confounding will occur and spurious racial differences will be interpreted despite matching groups on years of education. Therefore, the purpose of our next study (Manly, Jacobs, Touradji, Small, \& Stern, 2002) was to determine if discrepancies in quality of education could explain differences in cognitive test score between African American and white elders matched on years of education. We assessed English reading level using the Reading Recognition subtest from the Wide Range Achievement Test-Version 3 (Wilkinson, 1993). Participants were asked to name letters and pronounce words out of context. The words are listed in order of decreasing familiarity and increasing phonological complexity. WRAT-3 grade equivalent scores were derived from the normative values for people aged 65-74 from the manual.

Groups of 192 African American and 192 white 
TABLE 5

Demographics and reading level for African American and white elders

\begin{tabular}{lcccc}
\hline Variable & African American mean $(S D)$ & White mean $(S D)$ & t or $\chi^{2}$ & $p$ \\
\hline$N$ & 192 & 192 & & - \\
Female & $68.2 \%$ & $68.2 \%$ & - & .30 \\
Age & $73.9(5.8)$ & $74.6(5.9)$ & 1.0 & .55 \\
Years of education & $12.8(2.8)$ & $13.0(3.0)$ & 0.6 & $<.001$ \\
WRAT-3 reading score & $44.2(7.2)$ & $49.3(4.1)$ & 8.4 & \\
Reading level = reported grade & $47 \%$ & $56 \%$ & \\
Reading level $>$ reported grade & $20 \%$ & $38 \%$ & 48.98 & $<.001$ \\
Reading level $<$ reported grade & $33 \%$ & $7 \%$ & & \\
\hline
\end{tabular}

elders matched on educational attainment and sex distribution were formed through a stratified random sampling procedure. Table 5 compares the demographic characteristics of the two groups. When raw WRAT-3 scores were converted into grade-equivalent scores and compared with reported years of education, self-reported years of education gave an overestimate of actual reading level for a higher proportion of African Americans (33\%) than whites (7\%).

A MANCOVA revealed that African Americans scored significantly lower on the neuropsychological test battery overall as compared to whites. Follow-up univariate tests revealed significant differences between African Americans and whites on measures of word list learning and memory (SRT total immediate and delayed recall), figure memory (BVRT recognition), abstract reasoning (WAIS-R Similarities and DRS identities and oddities), letter fluency, category fluency, and visuospatial skill (Rosen drawings and BVRT matching). Table 6 shows racial group means and standard deviations on each test within the battery. WRAT-3 scores accounted for $34 \%$ of the variance of test scores overall. When WRAT-3 scores were entered into the multivariate model, the overall effect of race remained significant, $F(13,368)=2.7, p=.001$, but the effect size was significantly reduced. Followup univariate comparisons (Table 6) showed that after accounting for WRAT-3 score, racial differences on all measures except category fluency and the Rosen drawing test were no longer significant.

TABLE 6

Effect of race and WRAT-3 reading score on neuropsychological test score

\begin{tabular}{|c|c|c|c|c|c|c|}
\hline \multirow[b]{2}{*}{ Test } & \multirow[b]{2}{*}{ African American } & \multirow[b]{2}{*}{ White } & \multicolumn{2}{|c|}{ Effect of race } & \multicolumn{2}{|c|}{$\begin{array}{l}\text { After covarying for } \\
\text { WRAT reading score }\end{array}$} \\
\hline & & & $F$ & $p$ & $F$ & $p$ \\
\hline \multicolumn{7}{|l|}{ Learning/Memory } \\
\hline SRT total recall & $39.8(10.1)$ & $43.5(10.1)$ & 12.9 & .000 & 1.7 & .194 \\
\hline SRT delayed recall & $5.8(2.7)$ & $6.7(2.9)$ & 8.9 & .003 & 0.7 & .407 \\
\hline BVRT recognition memory & $7.4(1.8)$ & $8.1(1.5)$ & 20.4 & .000 & 2.5 & .115 \\
\hline \multicolumn{7}{|l|}{ Orientation } \\
\hline MMSE orientation & $9.7(0.7)$ & $9.8(0.5)$ & 3.5 & .062 & 1.0 & .310 \\
\hline \multicolumn{7}{|l|}{ Abstract reasoning } \\
\hline WAIS-R Similarities & $12.0(6.9)$ & $16.0(6.3)$ & 34.8 & .000 & 3.7 & .055 \\
\hline DRS identities \& oddities & $14.6(1.7)$ & $15.1(1.3)$ & 10.8 & .001 & 1.8 & .186 \\
\hline \multicolumn{7}{|l|}{ Language } \\
\hline Boston naming & $14.0(1.4)$ & $14.1(1.5)$ & 0.5 & .480 & 2.8 & .093 \\
\hline Letter fluency & $9.9(3.8)$ & $12.2(4.1)$ & 31.8 & .000 & 3.0 & .083 \\
\hline Category fluency & $14.6(3.8)$ & $16.8(3.8)$ & 31.4 & .000 & 10.0 & .002 \\
\hline BDAE repetition & $7.8(0.6)$ & $7.8(0.5)$ & 0.0 & .848 & 1.3 & .250 \\
\hline BDAE comprehension & $5.5(0.9)$ & $5.8(0.7)$ & 13.4 & .000 & 3.2 & .073 \\
\hline \multicolumn{7}{|l|}{ Visuospatial ability } \\
\hline Rosen drawing & $2.6(0.9)$ & $3.0(0.8)$ & 30.0 & .000 & 10.9 & .001 \\
\hline BVRT matching & $8.9(1.4)$ & $9.4(1.2)$ & 13.1 & .000 & 3.4 & .065 \\
\hline
\end{tabular}

SRT $=$ Selective Reminding Test; BVRT $=$ Benton Visual Retention Test; MMSE=Mini-Mental State Examination; WAIS-R $=$ Wechsler Adult Intelligence Scale-Revised; DRS=Dementia Rating Scale; BDAE=Boston Diagnostic Aphasia Examination. 
These findings suggest that the full extent of discrepancies in educational experience between African Americans and whites is not captured by a simple "highest grade attained" variable, and thus residual confounding may explain findings of "persistent" race effects after matching groups on years of education.

\section{CONCLUSION}

The research reviewed in this article demonstrates that literacy level is a crucial predictor of cognitive test performance among ethnically diverse elders. Not only does literacy level influence the specificity of neuropsychological measures, but it is also a powerful predictor of cognitive decline. Perhaps the most important finding from the studies described above is the large discrepancy between years of education and actual literacy level among ethnic minorities and immigrants. This suggests that race- or ethnicityspecific norms that correct for years of education may be less accurate than norms that correct for quality of education and are not specific to one racial or ethnic classification. Just as age and sex are expected to adjust expectations of an individual's performance, years of education have traditionally been used to adjust for changes in baseline knowledge, strategy, and skill that are accompanied by formal schooling. However, based on the results of this work, we propose that regardless of race/ethnicity, literacy measures educational experience more accurately than years of education, and thus is a superior assessment of the knowledge, strategy, and skills needed to perform well on traditional neuropsychological tasks. Test scores adjusted for reading level can be used to predict performance more accurately than if only years of education and racial classification were used.

Of course, both native ability and educational experience contribute to an individual's literacy level. However, the factors that determine the strength of each contribution tend to differ among ethnic or racial groups. When comparing between ethnic groups, differences in the availability of educational opportunity are likely to predominate. Racism, poverty, and other societal forces may have prevented some individuals with high native ability from gaining literacy skills, so literacy scores are a better proxy for quality of education in between-group comparisons. Within the same ethnic or racial group, disparities in educational opportunity may not be as strong, making literacy more likely to reflect ability to achieve academic success. In this case, literacy may be more appropriately used as a proxy for an individual's innate intellectual ability.

Literacy involves not only the ability to read and write script, but also the knowledge of how and in what context to apply literacy skills for specific purposes. All reading and writing tasks involve specific skills such as encoding language into graphic symbols, the visual and motor abilities involved in forming and decoding characters, words, or sentences, and retrieving word representations from memory (Scribner \& Cole, 1981). Since each of these skills could potentially have an effect on cognitive test performance, future investigations of literacy could measure these specific abilities in order to clarify their relationships to performance on neuropsychological measures. Assessment of the context in which literacy skills are used (or not used) may improve our knowledge of how literacy influences performance on measures of abstraction, comprehension, and problem solving. If cultural and individual factors can mediate the relationship between literacy and cognitive ability, the effect on neuropsychological test performance may not be straightforward or universal.

\section{REFERENCES}

Albert, M. S., Jones, K., Savage, C. R., Berkman, L., Seeman, T., Blazer, D., \& Rowe, J. W. (1995). Predictors of cognitive change in older persons: MacArthur studies of successful aging. Psychology and Aging, 10, 578-589.

Albert, S. M., \& Teresi, J. A. (1999). Reading ability, education, and cognitive status assessment among older adults in Harlem, New York City. American Journal of Public Health, 89, 95-97.

American Psychiatric Association (1987). Diagnostic and statistical manual of mental disorders. Washington, DC: American Psychiatric Press.

Ardila, A., Rosselli, M., \& Rosas, P. (1989). Neuropsychological assessment in illiterates: Visuospatial and memory abilities. Brain and Cognition, 11, 147-166.

Baker, F. M., Johnson, J. T., Velli, S. A., \& Wiley, C. (1996). Congruence between education and reading levels of older persons. Psychiatric Services, 47, 194-196.

Benton, A. L. (1955). The Visual Retention Test. New York: The Psychological Corporation.

Benton, A. L., \& Hamsher, K. D. (1976). Multilingual Aphasia Examination. Iowa City, IA: University of Iowa.

Blessed, G., Tomlinson, B. E., \& Roth, M. (1968). The association between quantitative measures of senile change in the cerebral grey matter of elderly subjects. British Journal of Psychology, 114, 797-811.

Boller, F., Mizutani, T., Roessmann, U., \& Gambetti, P. (1980). Parkinson's disease, dementia, and Alzheimer's 
disease: Clinicopathological correlations. Annals of Neurology, 1, 329-335.

Bonaiuto, S., Rocca, W. A., Lippi, A., Luciani, P., Turtu, F., Cavarzeran, F., \& Amaducci, L. (1990). Impact of education and occupation on prevalence of Alzheimer's disease (AD) and multi-infarct dementia (MID) in Appignano, Macerata Province, Italy. Neurology, 40, 346.

Bondi, M. W., Salmon, D. P., \& Butters, N. (1994). Neuropsychological features of memory disorders in Alzheimer's disease. In R. D. Terry, R. Katzman, \& K. L. Bick (Eds.), Alzheimer's disease (pp. 41-63). New York: Raven Press.

Bowirrat, A., Treves, T., Friedland, R. P., \& Korczyn, A. D. (2001). Prevalence of Alzheimer's type dementia in an elderly Arab population. European Journal of Epidemiology, 8, 119-123.

Burin, D. I., Jorge, R. E., Arizaga, R. A., \& Paulsen, J. S. (2000). Estimation of premorbid intelligence: The word accentuation test-Buenos Aires version. Journal of Clinical and Experimental Neuropsychology, 22, 677-685.

Buschke, H., \& Fuld, P. A. (1974). Evaluating storage, retention, and retrieval in disordered memory and learning. Neurology, 24, 1019-1025.

Butler, S. M., Ashford, J. W., \& Snowdon, D. A. (1996). Age, education, and changes in the MiniMental State Exam scores of older women: Findings from the Nun Study. Journal of the American Geriatrics Society, 44, 675-681.

Callahan, C. M., Hall, K. S., Hui, S. L., Musick, B. S., Unverzagt, F. W., \& Hendrie, H. C. (1996). Relationship of age, education, and occupation with dementia among a community-based sample of African Americans. Archives of Neurology, 53, 134-140.

Caramelli, P., Poissant, A., Gauthier, S., Bellavance, A., Gauvreau, D., Lecours, A. R., \& Joanette, Y. (1997). Educational level and neuropsychological heterogeneity in dementia of the Alzheimer type. Alzheimer Disease and Associated Disorders, 11, 9-15.

Chandra, V., Pandav, R., Dodge, H. H., Johnston, J. M., Belle, S. H., DeKosky, S. T., \& Ganguli, M. (2001). Incidence of Alzheimer's disease in a rural community in India: The Indo-US study. Neurology, 57, 985-989.

Chodosh, J., Reuben, D. B., Albert, M. S., \& Seeman, T. E. (2002). Predicting cognitive impairment in high-functioning community-dwelling older persons: MacArthur Studies of Successful Aging. Journal of the American Geriatrics Society, 50, 1051-1060.

Christensen, H., Korten, A. E., Jorm, A. F., Henderson, A. S., Jacomb, P. A., Rodgers, B., \& Mackinnon, A. J. (1997). Education and decline in cognitive performance: Compensatory but not protective. International Journal of Geriatric Psychiatry, 12, 323-330.

Dartigues, J. F., Gagnon, M., Michel, P., Letenneur, L., Commenges, D., Barberger-Gateau, P., Auriacombe S., Rigal, B., Bedry, R., Alperovitch, A., Orgogozo, J. M., Henry, P., Loiseau, P., Salamon, R., \& Groupe d'Etude Paquid (1991). Le programme de recherche paquid sur l'epidemiologie de la demence methodes et resultats initiaux. Review of Neurology, 147, 225-230.

Del Ser, T., Gonzalez-Montalvo, J.-I., MartinezEspinosa, S., Delgado-Villapalos, C., \& Bermejo,
F. (1997). Estimation of premorbid intelligence in Spanish people with the Word Accentuation Test and its application to the diagnosis of dementia. Brain and Cognition, 33, 343-356.

Evans, D. A., Beckett, L. A., Albert, M. S., Hebert, L. E., Scherr, P. A., Funkenstein, H. H., \& Taylor, J. O. (1993). Level of education and change in cognitive function in a community population of older persons. Annals of Epidemiology, 3, 71-77.

Farmer, M. E., Kittner, S. J., Rae, D. S., Bartko, J. J., \& Regier, D. A. (1995). Education and change in cognitive function: The epidemiologic catchment area study. Annals of Epidemiology, 5, 1-7.

Finley, G. E., Ardila, A., \& Roselli, M. (1991). Cognitive aging in illiterate Colombian adults: A reversal of the classical aging pattern? Revista Interamericana de Psicologia, 25, 103-105.

Folstein, M. F., Folstein, S. E., \& McHugh, P. R. (1975). 'Mini-mental State': A practical method for grading the cognitive state of patients for the clinician. Journal of Psychiatric Research, 12, 189-198.

Fratiglioni, L., Grut, M., Forsell, Y., Viitanen, M., Grafstrom, M., Holmen, K., Ericsson, K., Backman, L., Ahlbom, A., \& Winblad, B. (1991). Prevalence of Alzheimer's disease and other dementias in an elderly urban population: Relationship with age, sex and education. Neurology, 41, 1886-1892.

Gatz, M., Svedberg, P., Pederson, N. L., Mortimer, J. A., Berg, S., \& Johansson, B. (2001). Education and the risk of Alzheimer's disease: Findings from the study of dementia in Swedish twins. Journals of Gerontology, 56B, 292-300.

Goodglass, H., \& Kaplan, E. (1983). The assessment of aphasia and related disorders. Philadelphia: Lea \& Febiger.

Gurland, B. J., Wilder, D., Cross, P., Lantigua, R., Teresi, J. A., Barret, V., Stern, Y., \& Mayeux, R. (1995). Relative rates of dementia by multiple case definitions, over two prevalence periods, in three cultural groups. American Journal of Geriatric Psychiatry, 3, 6-20.

Hall, K. S., Gureje, O., Gao, S., Ogunniyi, A., Hui, S. L., Baiyewu, O., Unverzagt, F. W., Oluwole, S., \& Hendrie, H. C. (1998). Risk factors and Alzheimer's disease: A comparative study of two communities. Australian and New Zealand Journal of Psychiatry, 32, 698-706.

Hendrie, H. C. (2001). Exploration of environmental and genetic risk factors for Alzheimer's disease: The value of cross-cultural studies. Current Directions in Psychol Science, 10, 98-101.

Hill, L. R., Klauber, M. R., Salmon, D. P., Yu, E. S. H., Liu, W. T., Zhang, M., \& Katzman, R. (1993). Functional status, education, and the diagnosis of dementia in the Shanghai survey. Neurology, 43, $138-145$.

Jacobs, D. M., Sano, M., Albert, S., Schofield, P., Dooneief, G., \& Stern, Y. (1997). Cross-cultural neuropsychological assessment: A comparison of randomly selected, demographically matched cohorts of English- and Spanish-speaking older adults. Journal of Clinical and Experimental Neuropsychology, 19, 331-339.

Kaplan, E., Goodglass, H., \& Weintraub, S. (1983). Boston Naming Test. Philadelphia: Lea \& Febiger.

Kaufman, J. S., Cooper, R. S., \& McGee, D. L. (1997). 
Socioeconomic status and health in blacks and whites: The problem of residual confounding and the resilience of race. Epidemiology, 8, 621-628.

Kawas, C. H., \& Katzman, R. (1999). Epidemiology of dementia and Alzheimer's Disease. In R. D. Terry, R. Katzman, S. S. Sisodia, \& K. L. Bick (Eds.), Alzheimer's disease (pp.95-116). Philadelphia: Lippincott Williams \& Wilkins.

Korczyn, A. D., Kahana, E., \& Galper, Y. (1991). Epidemiology of dementia in Ashkelon, Israel. Neuroepidemiology, 10, 100.

Lecours, A. R., Mehler, J., Parente, M. A., Caldeira, A., Cary, L., Castro, M. J., Dehaut, F., Delgado, R., Gurd, J., Karmann, D. F., Jakubovitz, R., Osorio, Z., Cabral, L. S., \& Junquerira, A. M. S. (1987). Illiteracy and brain damage. 1. Aphasia testing in culturally contrasted populations (control subjects). Neuropsychologia, 25, 231-245.

Letenneur, L., Commenges, D., Dartigues, J. F., \& Barberger-Gateau, P. (1994). Incidence of dementia and Alzheimer's disease in elderly community residents of South-Western France. International Journal of Epidemiology, 23, 1256-1261.

Loewenstein, D. A., Arguelles, T., Arguelles, S., \& Linn-Fuentes, P. (1994). Potential cultural bias in the neuropsychological assessment of the older adult. Journal of Clinical and Experimental Neuropsychology, 16, 623-629.

Luria, A. R. (1976). Cognitive development, its cultural and social foundations. Cambridge, MA: Harvard University Press.

Manly, J. J., \& Jacobs, D. M. (2001). Future directions in neuropsychological assessment with African Americans. In F. R. Ferraro (Ed.), Minority and cross-cultural aspects of neuropsychological assessment (pp. 79-96). Leiden, The Netherlands: Swets \& Zeitlinger.

Manly, J. J., Jacobs, D. M., Sano, M., Bell, K., Merchant, C. A., Small, S. A., \& Stern, Y. (1999). Effect of literacy on neuropsychological test performance in nondemented, education-matched elders. Journal of the International Neuropsychological Society, 5, 191-202.

Manly, J. J., Jacobs, D. M., Touradji, P., Small, S. A., \& Stern, Y. (2002). Reading level attenuates differences in neuropsychological test performance between African American and White elders. Journal of the International Neuropsychological Society, 8 , 341-348.

Manly, J. J., Touradji, P., Tang, M. X., \& Stern, Y. (in press). Literacy and memory decline among ethnically diverse elders. Journal of Clinical and Experimental Neuropsychology.

Margo, R. A. (1985). Disenfranchisement, school finance, and the economics of segregated schools in the United States South, 1980-1910. New York: Garland Publishing.

Margo, R. A. (1990). Race and schooling in the South, 1880-1950: An economic history. Chicago: University of Chicago Press.

Mattis, S. (1976). Mental status examination for organic mental syndrome in the elderly patient. In L. Bellak \& T. B. Karasu (Eds.), Geriatric psychiatry (pp. 77-121). New York: Grune \& Stratton.

Mortel, K. F., Meyer, J. S., Herod, B., \& Thornby, J. (1995). Education and occupation as risk factors for dementia of the Alzheimer and ischemic vascular types. Dementia, 6, 55-62.

Mortimer, J. A. (1988). Do psychosocial risk factors contribute to Alzheimer's disease. In A. S. Henderson \& J. H. Henderson (Eds.), Etiology of Dementia of Alzheimer's Type (pp.39-52). Chichester, UK: John Wiley.

Nelson, H. E. (1982). The National Adult Reading Test (NART): Test Manual. Bury St Edmunds, UK: Thames Valley Test Company.

Nelson, H. E., \& O'Connell, A. (1978). Dementia: The estimation of premorbid intelligence levels using the National Adult Reading Test. Cortex, 14, 234-244.

Ott, A., Breteler, M. M., Van Harskamp, F., Claus, J. J., Van der Cammen, T. J., Grobbee, D. E., \& Hofman, A. (1995). Prevalence of Alzheimer's disease and vascular dementia: Association with education. The Rotterdam study. British Medical Journal, 310, 970-973.

Parasuraman, R., \& Haxby, J. (1993). Attention and brain function in Alzheimer's disease: A review. Neuropsychology, 7, 242-272.

Prencipe, M., Casini, A. R., Ferretti, C., Lattanzio, M. T., Fiorelli, M., \& Culasso, F. (1996). Prevalence of dementia in an elderly rural population: Effects of age, sex, and education. Journal of Neurology, Neurosurgery and Psychiatry, 60, 628-633.

Reis, A., \& Castro-Caldas, A. (1997). Illiteracy: A cause for biased cognitive development. Journal of the International Neuropsychological Society, 3, 444-450.

Reis, A., Guerreiro, M., \& Castro-Caldas, A. (1994). Influence of educational level of non-brain-damaged subjects on visual naming capacities. Journal of Clinical and Experimental Neuropsychology, 16, 939-942.

Rosen, W. (1981). The Rosen Drawing Test. Bronx, NY: Veterans Administration Medical Center.

Rosselli, M., Ardila, A., \& Rosas, P. (1990). Neuropsychological assessment in illiterates. II. Language and praxic abilities. Brain and Cognition, 12, 281-296.

Satz, P., Morgenstern, H., Miller, E. N., Selnes, O. A., McArthur, J. C., Cohen, B. A., Wesch, J., Becker, J. T., Jacobson, L., D'Elia, L. F., Van Gorp, W., \& Visscher, B. (1993). Low education as a possible risk factor for cognitive abormalities in HIV-1: Findings from the Multicenter AIDS Cohort Study (MACS). Journal of Acquired Immune Deficiency Syndromes, 6, 503-511.

Scribner, S., \& Cole, M. (1981). The psychology of literacy. Cambridge, MA: Harvard University Press.

Smith, J. P. (1984). Race and human capital. American Economic Review, 4, 685-698.

Smith, J. P., \& Welch, F. (1977). Black-White male wage ratios: 1960-1970. American Economic Review, 67, 323-328.

Snowdon, D. A., Ostwald, S. K., \& Kane, R. L. (1989). Education, survival and independence in elderly Catholic sisters, 1936-1988. American Journal of Epidemiology, 130, 999-1012.

Stern, Y. (2002). What is cognitive reserve? Theory and research application of the reserve concept. Journal of the International Neuropsychological Society, 8 , 448-460.

Stern, Y., Albert, S., Tang, M. X., \& Tsai, W. Y. (1999). Rate of memory decline in AD is related to education and occupation: Cognitive reserve? Neurology, 53, 1942-1947. 
Stern, Y., Andrews, H., Pittman, J., Sano, M., Tatemichi, T., Lantigua, R., \& Mayeux, R. (1992). Diagnosis of dementia in a heterogeneous population. Development of a neuropsychological paradigm-based diagnosis of dementia and quantified correction for the effects of education. Archives of Neurology, 49, 453-460.

Stern, Y., Gurland, B., Tatemichi, T. K., Tang, M. X., Wilder, D., \& Mayeux, R. (1994). Influence of education and occupation on the incidence of Alzheimer's disease. Journal of the American Medical Association, 271, 1004-1010.

Stern, Y., Tang, M. X., Denaro, J., \& Mayeux, R. (1995). Increased risk of mortality in Alzheimer's disease patients with more advanced educational and occupational attainment. Annals of Neurology, 37, 590-595.

Sulkava, R., Wikstrom, J., Aromaa, A., Raitasalo, R., Lahtinen, V., Lahtela, K., \& Palo, J. (1985). Prevalence of severe dementia in Finland. Neurology, 35, 1025-1029.

Teri, L., McCurry, S. M., Edland, S. D., Kukull, W. A., \& Larson, E. B. (1995). Cognitive decline in Alzheimer's disease: A longitudinal investigation of risk factors for accelerated decline. Journals of Gerontology: Biological Sciences and Medical Sciences, 50A, M49-M55.

Troster, A. I., Butters, N., Salmon, D. P., Cullum, C. M., Jacobs, D., Brandt, J., \& White, R. F. (1993). The diagnostic utility of savings scores: Differentiating Alzheimer's and Huntington's diseases with the Logical Memory and Visual Reproduction tests. Journal of Clinical and Experimental Neuropsychology, 15, 773-788.

Unverzagt, F. W., Hui, S. L., Farlow, M. R., Hall, K. S., \& Hendrie, H. C. (1998). Cognitive decline and education in mild dementia. Neurology, 50, 181-185.
Vygotsky, L. S. (1962). Thought and language. Cambridge, MA: MIT Press.

Vygotsky, L. S. (1978). Mind in society: The development of higher psychological processes. Cambridge, MA: Harvard University Press.

Wechsler, D. (1981). Wechsler Adult Intelligence ScaleRevised. New York: The Psychological Corporation.

Welch, F. (1966). Measurement of the quality of education. American Economic Review, 56, 379-392.

Welch, F. (1973). Black-White differences in returns to schooling. American Economic Review, 63, 893-907.

Welsh, K. A., Butters, N., Hughes, J. P., Mohs, R. C., \& Heyman, A. (1992). Detection and staging of dementia in Alzheimer's disease: Use of the neuropsychological measures developed for the Consortium to Establish a Registry for Alzheimer's Disease. Archives of Neurology, 49, 448-452.

White, L., Katzman, R., Losonczy, K., Salive, M., Wallace, R., Berkman, L., Taylor, J., Fillenbaum, G., \& Havlik, R. (1994). Association of education with incidence of cognitive impairment in three established populations for epidemiological studies of the elderly. Journal of Clinical Epidemiology, 47, 363-374.

Whitfield, K. E., \& Baker-Thomas, T. (1999). Individual differences in aging minorities. International Journal of Aging and Human Development, 48, 73-79.

Wilkinson, G. S. (1993). Wide Range Achievement Test 3 - Administration Manual. Wilimington, DE: Jastak Associates.

Zhang, M., Katzman, R., Salmon, D., Jin, H., Cai, G., Wang, Z., Qu, G., Grant, I., Yu, E., Levy, P., Klauber, M. R., \& Liu, W. T. (1990). The prevalence of dementia and Alzheimer's disease in Shanghai, China: Impact of age, gender and education. Annals of Neurology, 27, 428-437. 